Check for updates

Cite this: RSC Adv., 2019, 9, 22627

\title{
Nano-architecture of silica nanoparticles as a tool to tune both electrochemical and catalytic behavior of $\mathrm{Ni}^{\prime \prime} \mathrm{aSiO}_{2}$
}

\author{
Mikhail N. Khrizanforov, (D)* Svetlana V. Fedorenko, Asia R. Mustafina, \\ Vera V. Khrizanforova, (D) Kirill V. Kholin, Irek R. Nizameev, Tatyana V. Gryaznova, (D) \\ Valeriya V. Grinenko (D) and Yulia H. Budnikova (D)
}

\begin{abstract}
The present work introduces a facile synthetic route for efficient doping of $\left[\mathrm{Ni}^{\prime \prime}(\mathrm{bpy})_{x}\right]$ into silica nanoparticles with various sizes and architectures. Variation of the latter results in different concentrations of the $\mathrm{Ni}^{l l}$ complexes at the interface of the composite nanoparticles. The UV-Vis analysis of the nanoparticles reveals changes in the inner-sphere environment of the $\mathrm{Ni}^{l l}$ complexes when embedded into the nanoparticles, while the inner-sphere of $\mathrm{Ni}^{\mathrm{Il}}$ is invariant for the nanoparticles with different architecture. Comparative analysis of the electrochemically generated redox transformations of the $\mathrm{Ni}^{\text {ll }}$ complexes embedded in the nanoparticles of various architectures reveals the latter as the main factor controlling the accessibility of $\mathrm{Ni}^{\prime \prime}$ complexes to the redox transitions which, in turn, controls the electrochemical behavior of the nanoparticles. The work also highlights an impact of the nanoparticulate architecture in catalytic activity of the $\mathrm{Ni}^{\prime \prime}$ complexes within the different nanoparticles in oxidative $\mathrm{C}-\mathrm{H}$ fluoroalkylation of caffeine. Both low leakage and high concentration of the $\mathrm{Ni}^{\prime \prime}$ complexes at the interface of the composite nanoparticles enables fluoroalkylated caffeine to be obtained in high yields under recycling of the nanocatalyst five times at least.
\end{abstract}

Received 7th May 2019

Accepted 26th June 2019

DOI: $10.1039 / c 9 r a 03421 \mathrm{~h}$

rsc.li/rsc-advances makes them promising alternate to noble metal-based nanoparticles, although the homogeneous catalysis by $\mathrm{Ni}^{\mathrm{III} / \mathrm{II} / \mathrm{I} /}$ ${ }^{0}$ complexes suffers from the lack of recyclability. The embedding of metal complexes into silica or other matrix is a wellknown facile and efficient approach of converting molecular metal complexes to their nanoparticular forms..$^{35-38}$ Moreover, the catalytic efficiency of such composite silica nanoparticles has been already exemplified. ${ }^{35-38}$ However, the nanoparticulate features controlling catalytic efficiency of the composite nanoparticles are still insufficiently recognized.

Alkaline-catalyzed hydrolysis of TEOS is most convenient synthetic route for gaining in spherical shape and universe size of silica nanoparticles (SNs). ${ }^{39-41}$ The simple addition of any dopants to the synthetic mixture results in their embedding into the silica confinement in the form of ultra-small nanoaggregates. ${ }^{35,42}$ This forms the plum-pudding architecture of the nanoparticles which, in turn, can be modified by predominant localization of dopants in core or interfacial zones of nanoparticles. ${ }^{43}$ Architecture of SNs doped by different functional molecules is of great impact on the functionality of the nanoparticles exemplified by sensing and imaging abilities. ${ }^{43-45}$

Catalytic behavior of such nanoparticles require enough accessibility of the doped complexes to electrochemically induced reduction or oxidation which, in turn, is a reason for specific requirements to both a size and architecture of the nanoparticles. It is worth noting that our previous report reveals 
doping of $\mathrm{Ni}^{\mathrm{II}}$ complexes into silica nanoparticles with further electrochemical generation of the $\mathrm{Ni}^{\mathrm{III}}$ complexes as facile approach for synthesis of stable in time composite nanoparticles (90-100 nm) with rather high and recyclable catalytic activity in oxidative C-H alkylation..$^{35}$ Nevertheless, the reported results remain unclear the issue on the effect of size and architecture of the composite nanoparticles on their catalytic behavior.

The present work is aimed at highlighting the features that control catalytic behavior of the $\mathrm{Ni}(\mathrm{II})$-doped composite SNs in the oxidative $\mathrm{C}-\mathrm{H}$ fluoroalkylation of caffeine. Thus, an impact of the size and nano-architecture of the composite nanoparticles on their catalytic behavior is discussed herein. The nanoparticulate architecture is changed by variation of concentration and/or distribution of the $\mathrm{Ni}^{\mathrm{II}}$ complexes within the silica spheres for differentiating interfacial accessibility of the $\mathrm{Ni}^{\mathrm{II}}$ complexes to oxidation and interactions with substrates. For this reason, the redox potential values of the $\mathrm{Ni}^{\mathrm{iI}}$ complexes encapsulated into the nanoparticles of the various architecture are discussed in correlation with their catalytic behavior. The synthetic approaches for controlling both size and nano-architecture of the composite nanoparticles are also introduced.

\section{Results and discussion}

Stöber procedure opens great opportunities for modification of the silica spheres size by variation of the synthetic conditions. ${ }^{39-41}$ The time conditions variation from 30 to 60 and 120 minutes at the TEOS : Ni $(521: 1)$ ratio enables to differentiate the size of the SNs from 31-46 nm (SNs-1) to 50-79 $\mathrm{nm}$ (SNs-2) and $60-90 \mathrm{~nm}$ (SNs-3). The TEM images presented in Fig. 1 illustrate the difference between the synthesized SNs. The content of $\mathrm{Ni}$ in the composite nanoparticles was quantitatively evaluated by ICP-OES technique, while the use of EDS method (Fig. 2) provides additional confirmation of the presence of $\mathrm{Ni}$ in the composite nanoparticles. The $\mathrm{Si}: \mathrm{Ni}$ molar ratios calculated from the ICP-OES data (Table 1) also indicate the

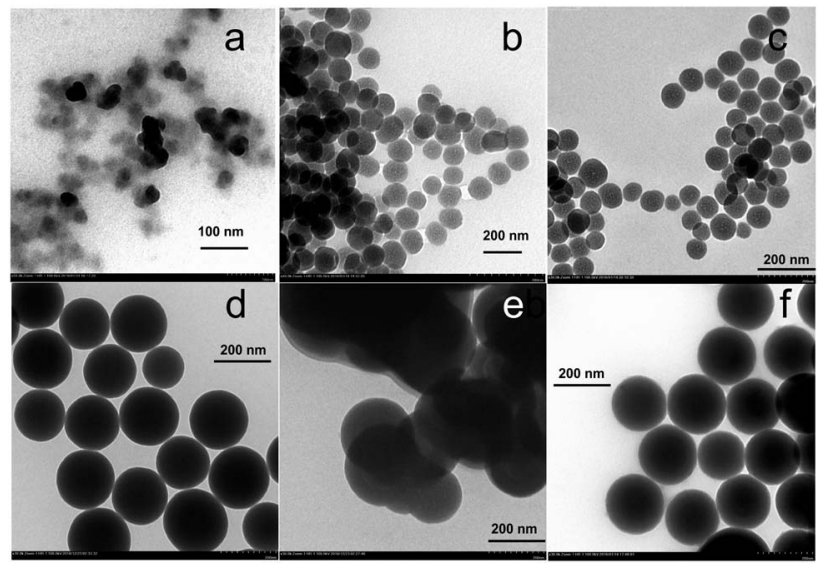

Fig. 1 TEM images of silica nanoparticles $\mathrm{SNs} 1-6$, doped $\mathrm{Ni}\left(\mathrm{BF}_{4}\right)_{2}$ bpy $_{3}$, where a - SNs-1, b - SNs-2, c - SNs-3, d - SNs-4, e - SNs-5, fSNs-6.

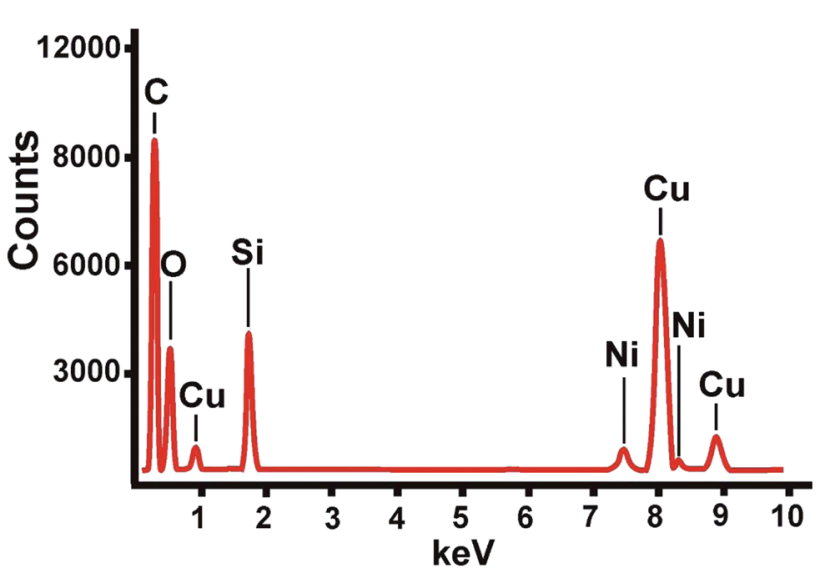

Fig. 2 TEM-EDX spectra of NP type 2.

difference between the synthesized nanoparticles. It is worth noting that the content of $\mathrm{Ni}^{\mathrm{II}}$ tends to decrease with the growth of the SNs, which, in turn, reveals the inhomogeneous distribution of the $\mathrm{Ni}^{\mathrm{II}}$ complexes within silica spheres. In particular, concentration of the complexes in the interfacial zone of the SNs tends to decrease on going from SNs-1 to SNs-2 and SNs-3.

The further modification of the Stöber procedure ${ }^{39}$ was done by the increased TEOS : Ni $(782: 1)$ ratio under the growth of the silica spheres for six hours for the greater size of the SNs. Indeed, the synthesized SNs-4 are $189 \mathrm{~nm}$ sized with the smaller Ni content. The SNs-5 and SNs- 6 were synthesized through the two-step addition of TEOS in order to minimize the concentration of the $\mathrm{Ni}^{\mathrm{II}}$ complexes in the interfacial zone of the nanoparticles. For this reason, the SNs-4 grown within six hours were washed from the unreacted $\mathrm{Ni}^{\mathrm{II}}$ complexes, TEOS and ammonia with further addition of TEOS and ammonia without $\mathrm{Ni}^{\mathrm{II}}$ complex. Indeed, the modified procedure enabled to get SNs-5 and SNs-6 which differentiates from each other by thicker additional silica adlayer for SNs-6 versus SNs-5. The thickness of the additional silica adlayer was, in turn, varied by the amount of the TEOS added at the second step. The variations of the synthetic procedure resulting in different architectures of the nanoparticles are illustrated by the Scheme 1, while their TEM images in the Fig. 1 were used for the size values specification.

It is also worth noting that the thickening of the external silica adlayer on going from the SNs-4 to the SNs-5(6) results in the further decrease of the Ni-content (Table 1). Moreover, the two-step procedure is the obvious prerequisite for the smaller

Table 1 The correlation of the average size (TEM) and molar ratio $\mathrm{Si}$ : Ni of the obtained nanoparticles SNs-1-SNs-6

\begin{tabular}{llll}
\hline & & \multicolumn{2}{c}{ Molar ratio of $\mathrm{Si}: \mathrm{Ni}, \pm 10 \%$} \\
\cline { 3 - 4 } Sample & $D(\mathrm{TEM})$ & $\mathrm{Si}$ & $\mathrm{Ni}$ \\
\hline SNs-1 & $31-46 \mathrm{~nm}$ & 1 & $0.02 \pm 0.002$ \\
SNs-2 & $50-79 \mathrm{~nm}$ & 1 & $0.012 \pm 0.0012$ \\
SNs-3 & $60-90 \mathrm{~nm}$ & 1 & $0.0053 \pm 0.0005$ \\
SNs-4 & $189 \mathrm{~nm}$ & 1 & $0.00126 \pm 0.0001$ \\
SNs-5 & $\sim 200 \mathrm{~nm}$ & 1 & $0.00235 \pm 0.0002$ \\
SNs-6 & $204-241 \mathrm{~nm}$ & 1 & $0.00138 \pm 0.0001$
\end{tabular}




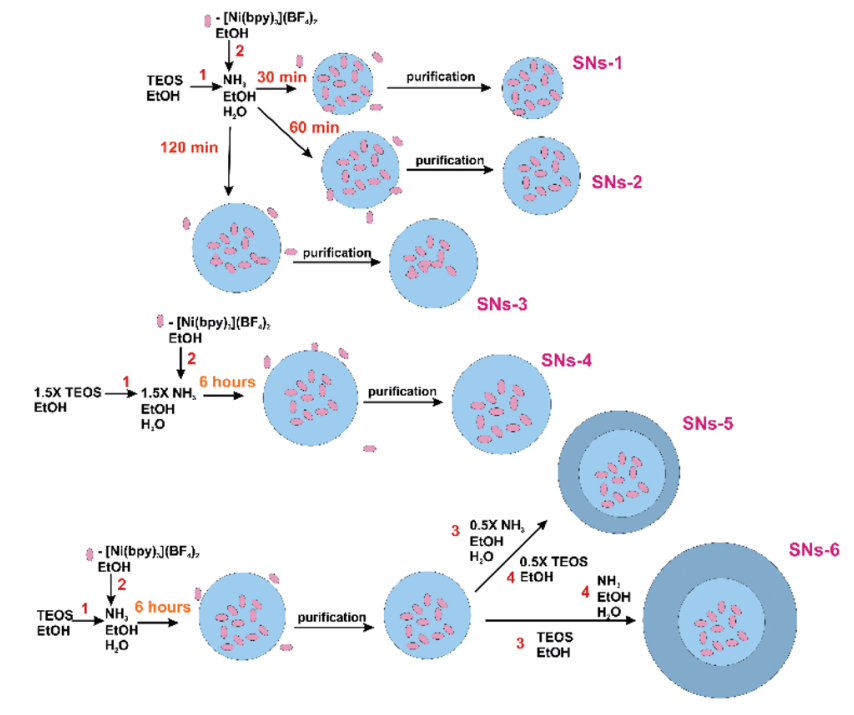

Scheme 1 Schematic representation of SNs-1-SNs-6 synthesis.

interfacial concentration of the $\mathrm{Ni}^{\mathrm{II}}$ complexes in the SNs-5 and SNs-6 versus SNs-4.

It is worth noting the tendency revealed in our previous report that the doping of the initial $\left[\mathrm{Ni}^{\mathrm{II}}(\mathrm{bpy})_{3}\right]$ complexes into the SNs is accompanied by their partial degradation to $\left[\mathrm{Ni}^{\mathrm{II}}(\mathrm{bpy})_{x}\right](x<2)$. The degradation is easily revealed by the changed spectral pattern of the complexes within the SNs versus the $\left[\mathrm{Ni}^{\mathrm{II}}(\mathrm{bpy})_{3}\right]$, while its comparison with that of $\left[\mathrm{Ni}^{\mathrm{II}}(\mathrm{bpy})\right]$ in the solutions (Fig. 3) confirms the partial degradation resulted from the doping procedure. Nevertheless, the spectral patterns revealed for the SNs-1(2-6) are rather similar, which indicates that half of an hour is enough for the partial degradation of the initial complex.

The spectral data in Fig. 3 represent the low-intensity bands in the electronic spectra of the supernatant solutions after the continuous stirring of the nanoparticles in the acetonitrile solutions which provide the indication of very low leaching of the complex from the SNs to the supernatant solutions (Fig. 4).

Concluding the subsection, it is worth noting that a half of an hour is enough for the embedding of the major part of the $\mathrm{Ni}^{\mathrm{iI}}$ complex into silica spheres, although their size is rather small and the uniformity in the size is also small (30-46 nm). The longer time is required for the synthesis of the greater sized

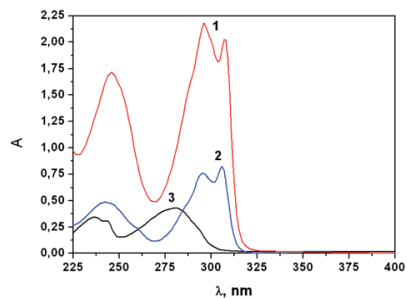

(a)

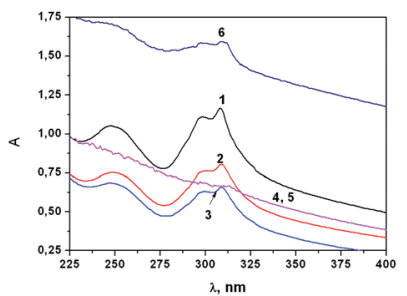

(b)
Fig. 3 The absorption spectra (a) of the obtained silica nanoparticles SNs-1-SNs-6, doped [Ni"(bpy) $)_{x}$ (1-6), where 1 - SNs-1, 2 - SNs-2, 3 SNs-3, 4 - SNs-4, 5 - SNs-5, 6 - SNs- 6 in $\mathrm{CH}_{3} \mathrm{CN}\left(C=0.2 \mathrm{~g} \mathrm{~L}^{-1}\right)$; (b) 1 - $\left[\mathrm{Ni}^{\prime \prime}(\mathrm{bpy})_{3}\right], 2-\left[\mathrm{Ni}^{\prime \prime}(\mathrm{bpy})\right]\left(\mathrm{C}_{\left[\mathrm{Ni}^{\prime \prime}(\mathrm{bpy})_{x}\right]}=510^{-5} \mathrm{M}\right), 3-$ bpy in $\mathrm{CH}_{3} \mathrm{CN}(\mathrm{C}$ $=110^{-5} \mathrm{M}$ )

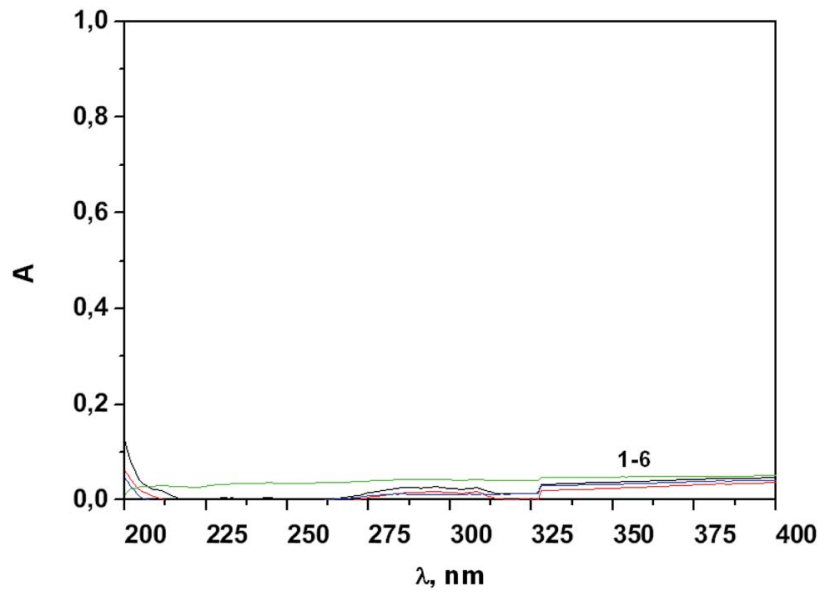

Fig. 4 The absorption spectra of the supernatants after 1 hour of continuous stirring followed by the separation of SNs-1-6 (1-6) $(0.2 \mathrm{~g}$ $\mathrm{L}^{-1}$ ) in $\mathrm{CH}_{3} \mathrm{CN}$.

silica spheres, while the $\mathrm{Ni}$ : $\mathrm{Si}$ ratio tends to decrease with the size growth. The results point to predominant localization of the $\mathrm{Ni}^{\mathrm{II}}$ complexes in the core zones of the silica spheres, while the concentration of the complexes in the interfacial zone tends to decrease with the size growth. It is also worth noting that regardless of the time conditions $\mathrm{Ni}^{\mathrm{II}}$ complexes embedded into the silica spheres tend to lose one or two bpy ligands due to the ligand substitution processes. The latter are very difficult to specify, since both ammonia and hydroxyl anions existing in the synthetic mixture and $\mathrm{Si}-\mathrm{O}^{-}$groups at the silica surface can be bound with $\left[\mathrm{Ni}^{\mathrm{II}}(\mathrm{bpy})_{x}\right]$ in the inner- or outer-sphere modes.

\section{Electrochemical study}

Accurate comparative analysis of nickel(II) complexes redox behavior under their encapsulation into variously sized silica nanoparticles is rather complicated task because of difference in their diffusion rates. However, cyclic voltammetry (CV) using a phosphonium salt based paste electrode is very promising alternate to cyclic voltammetry in solutions which was previously proven for analyzing insoluble and poorly soluble complexes. Thus, the use of such electrochemical technique enabled to get the CV curves for both SNs-1(2-6) and initial $\left[\mathrm{Ni}(\mathrm{bpy})_{3}\right]\left(\mathrm{BF}_{4}\right)_{2}$ complex in the same conditions (Fig. 5 and Table 2). We used semi-derivative voltammetry to confirm the redox properties for all SNs-1(2-6) and initial $\left[\mathrm{Ni}(\mathrm{bpy})_{3}\right]\left(\mathrm{BF}_{4}\right)_{2}$ complex (Fig. 7). The semi-derivative voltammetry shows the reversibility of redox transitions $\mathrm{Ni}(\mathrm{II}) \leftrightarrow \mathrm{Ni}(0), \mathrm{Ni}(\mathrm{II}) \leftrightarrow \mathrm{Ni}($ III), $\mathrm{Ni}($ III) $\leftrightarrow \mathrm{Ni}(\mathrm{Iv}), \mathrm{Ni}(\mathrm{II}) \leftrightarrow \mathrm{Ni}(\mathrm{IV})$.

The electrochemical reduction and oxidation of the $\mathrm{Ni}^{\mathrm{II}}$ complexes in both molecular and nanoparticulate forms occurs up to $\mathrm{Ni}^{0}$ and $\mathrm{Ni}^{\mathrm{III}}$ correspondingly with one exception for SNs6 , where the electrochemical behavior is manifested by one twoelectron oxidation step $\mathrm{Ni}^{\mathrm{II}} / \mathrm{Ni}^{\mathrm{IV}}$. The significant difference in the potential values of $\mathrm{SNs}-1$ and $\left[\mathrm{Ni}(\mathrm{bpy})_{3}\right]\left(\mathrm{BF}_{4}\right)_{2}$ correlates with the differences in the inner-sphere of $\mathrm{Ni}^{\mathrm{II}}$ arisen from the substitution of one or two bpy ligands by $\mathrm{Si}-\mathrm{O}^{-}$donor groups. 


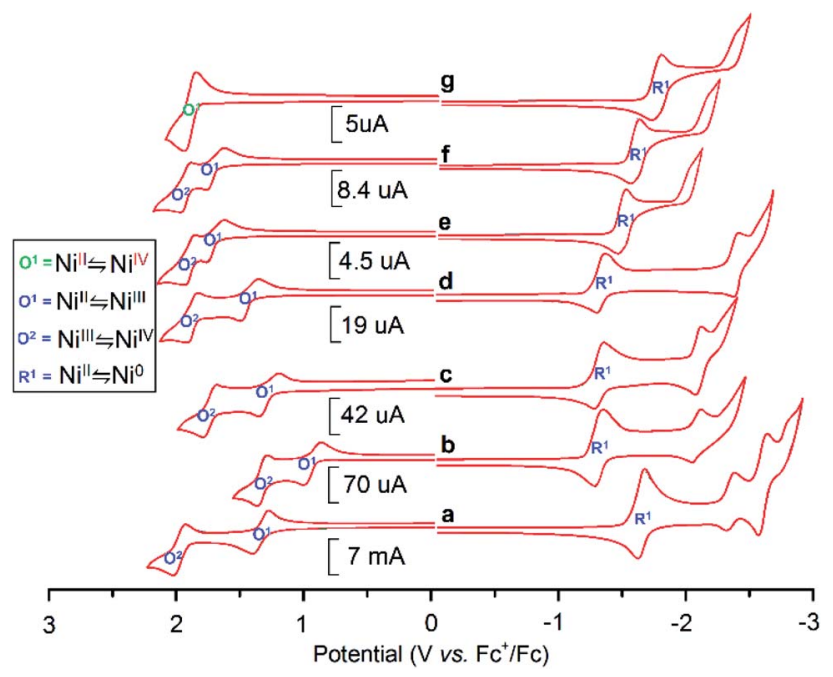

Fig. $5 \mathrm{CVs}$ for (a) [Ni"(bpy) ${ }_{3}$ ] (b) SNs-1; (c) SNs-2; (d) SNs-3; (e) SNs-4, (f) SNs-5, (g) SNs-6 WE: CPE, $\mathrm{CH}_{3} \mathrm{CN}, 10^{-1} \mathrm{M} \mathrm{Bu}_{4} \mathrm{NBF}_{4}$ potentials vs. $\mathrm{Ag} / \mathrm{AgCl}$ recalculated to $\mathrm{Fc}^{+} / \mathrm{Fc}$.

Table 2 The potentials for Fig. 5 Conditions: $25^{\circ} \mathrm{C}$, working electrode: $\mathrm{CPE}$ (graphite + ionic liquid + [Ni particles]), $\mathrm{Bu}_{4} \mathrm{NBF}_{4}$ background salt, $\mathrm{CH}_{3} \mathrm{CN}, 100 \mathrm{mV} \mathrm{s}^{-1}$. Potentials vs. Fc $/ \mathrm{Fc}$

\begin{tabular}{llllll}
\hline & Reduction & & & \multicolumn{2}{c}{ Oxidation } \\
\cline { 2 - 3 } & ${ }^{1} E_{\mathrm{p}}^{\mathrm{c}} / E_{\mathrm{p}}^{\mathrm{a}}, \mathrm{V}$ & ${ }^{2} E_{\mathrm{p}}^{\mathrm{c}} / E_{\mathrm{p}}^{\mathrm{a}}, \mathrm{V}$ & & ${ }^{1} E_{\mathrm{p}}^{\mathrm{a}} / E_{\mathrm{p}}^{\mathrm{c}}, \mathrm{V}$ & ${ }^{2} E_{\mathrm{p}}^{\mathrm{a}} / E_{\mathrm{p}}^{\mathrm{c}}, \mathrm{V}$ \\
\hline SNs-1 & $-1.40 /-1.28$ & $-2.15 /-2.03$ & & $1.03 / 0.95$ & $1.50 / 1.40$ \\
SNs-2 & $-1.41 /-1.32$ & $-2.21 /-2.15$ & & $1.49 / 1.40$ & $1.83 / 1.76$ \\
SNs-3 & $-1.45 /-1.39$ & $-2.56 /-2.50$ & & $1.51 / 1.44$ & $1.90 / 1.83$ \\
SNs-4 & $-1.55 /-1.49$ & - & $1.81 / 1.60$ & $1.87 / 1.83$ \\
SNs-5 & $-1.61 /-1.55$ & - & $1.84 / 1.62$ & $1.87 / 1.84$ \\
SNs-6 & $-1.92 /-1.85$ & - & & $1.85 / 1.79$ & - \\
{$\left[\right.$ Ni $\left.^{1 \mathrm{I}}(\mathrm{bpy})_{3}\right]$} & $-1.65 /-1.59$ & $-2.34 /-2.27$ & & $1.34 / 1.26$ & $2.01 / 1.95$
\end{tabular}

The potential values of SNs-1(2-6) reveal significant dependence on their size, although the spectral properties of the nanoparticles (Fig. 3) indicate the similarity in the inner-sphere environment of $\mathrm{Ni}^{\mathrm{II}}$ ions within SNs-1(2-6). However, a redox behavior of transition metal complexes is greatly affected by polarity or specific interactions arisen from their outer-sphere environment. ${ }^{46-50}$ It is worth assuming that the difference in size and nanoparticulate architecture of SNs-1(2-6) leads to the different distribution of the doped complexes between the interfacial and core zones of the SNs. It is also worth noting that the complexes located in the interfacial zone are more accessible to any external stimulus than the complexes within the core zone of nanoparticles. ${ }^{\mathbf{4 3 , 4 4 , 5 1}}$ Moreover, the extent of the interfacial complexes tends to increase with the decrease in size of the nanoparticles. ${ }^{52}$

The similar tendency should be valid for $\left[\mathrm{Ni}^{\mathrm{II}}(\mathrm{bpy})_{x}\right]$ complexes inside the growing in size (Table 1) SNs-1(2-6). The tendency is enhanced by the specific synthetic conditions applied in obtaining of SNs-1(2-6). In particular, the increase in size of SNs-1(2-6) results from both longer time for their growth and the greater TEOS concentrations, while the concentration of initial $\mathrm{Ni}^{\mathrm{II}}$ complex added at the beginning of the synthesis remains invariant. This results in the dramatic decrease in the concentration of the interfacial $\mathrm{Ni}^{\mathrm{II}}$ complexes on going from SNs-1 to SNs-6. The results point to correlation of the electrochemical potential values of $\mathrm{Ni}^{\mathrm{II}}$ complexes inside $\mathrm{SNs}-1(2-6)$ with their nanoarchitecture.

Taking into account electrochemical reversibility of the redox transformations of the $\mathrm{Ni}^{\mathrm{II}}$ complexes inside SNs-1(2-6) (Fig. 5) the corresponding redox potential values (Table 2) provide a direct measure of thermodynamic feasibility of the electrochemical behavior of the $\mathrm{Ni}^{\mathrm{II}}$ complexes inside the nanoparticles. This, in turn, is the prerequisite for evaluating a difference between the energies of the boundary molecular orbitals for the nanoparticulate forms of $\mathrm{Ni}^{\mathrm{II}}$ complexes from the electrochemical gap $\Delta E$. The latter is the difference between standard redox potentials, or $E_{1 / 2}$ of oxidation and reduction which is designated by eqn (1).

$$
\Delta E=E_{1 / 2}^{\mathrm{Ox}}-E_{1 / 2}^{\mathrm{Red}}
$$

The importance of $\Delta E$ values was illustrated by the previous reports on organic compounds highlighting a correlation between the energy required to add one electron to a molecule, the standard reduction potential, and the energy of the LUMO. ${ }^{51}$

The energy of the LUMO can be approximated by the electron affinity, which is the energy required to add an electron to an atom or molecule in the gas phase. In a similar fashion, correlations have been found for organic molecules between the standard oxidation potentials and the ionization potentials. ${ }^{31,52-56}$ Fig. 6 illustrates the correlation of the $\Delta E$ values with the size of the nanoparticles, since the growth in size, in turn, correlates with localization of the $\mathrm{Ni}^{\mathrm{II}}$ complexes within the silica spheres. In our case, the smallest particles are characterized by the smallest value of $\Delta E$, and it is much smaller than $\Delta E$ of the precursor, which is $\mathrm{Ni}\left(\mathrm{BF}_{4}\right)_{2} \mathrm{bpy}_{3}$ complex (Fig. 5). Further, with an increase in the particle size, the $\Delta E$ gap expands due to the growth of both anodic and cathodic potentials simultaneously. In this case, the difference between the potentials of the consecutive oxidation $\mathrm{Ni}^{\mathrm{II}} / \mathrm{Ni}^{\mathrm{III}} / \mathrm{Ni}^{\mathrm{IV}}$ decreases. As a result, for the SNs of the largest size (SNs-6), only

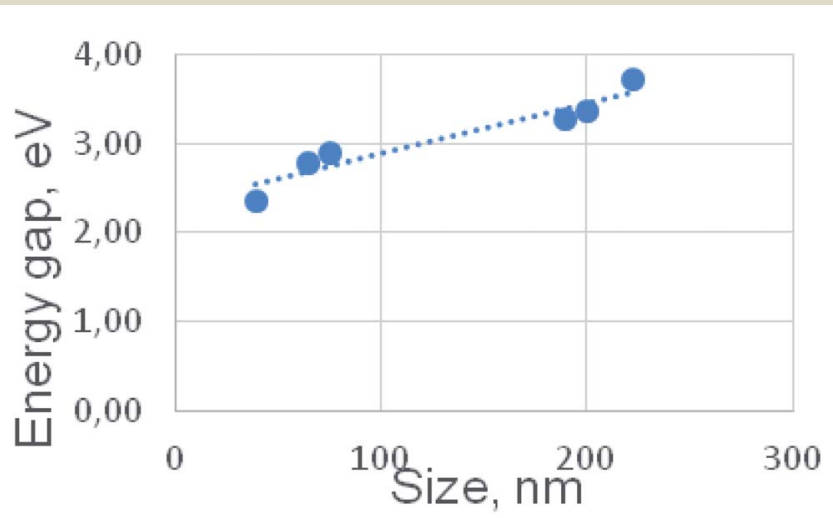

Fig. 6 The dependence of the electrochemical gap versus the size of Ni nanoparticles. 


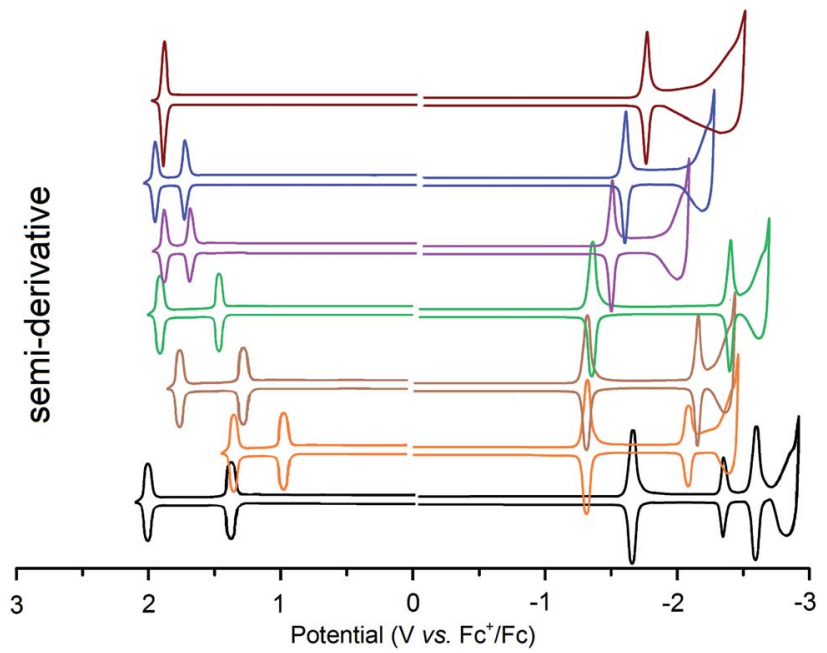

Fig. 7 Semi-derivative cyclic voltammetry for [ $\left.\mathrm{Ni}^{\prime \prime}(\mathrm{bpy})_{3}\right]$ (black); SNs1 (orange); SNs-2 (light brown); SNs-3 (green); SNs-4 (violet), SNs-5 (blue), SNs-6 (brown) WE: CPE, $\mathrm{CH}_{3} \mathrm{CN}, 10^{-1} \mathrm{M} \mathrm{Bu}_{4} \mathrm{NBF}_{4}$ potentials vs. $\mathrm{Ag} / \mathrm{AgCl}$ recalculated to $\mathrm{Fc}^{+} / \mathrm{Fc}$; scan rate: $0.1 \mathrm{~V} \mathrm{~s}^{-1}$.

one stage of anodic oxidation is observed with synchronous transfer of two electrons, $\mathrm{Ni}^{\mathrm{II}} / \mathrm{Ni}^{\mathrm{IV}}$.

\section{Ni-catalyzed oxidative C-H fluoroalkylation of caffeine}

Joint electrolysis of caffeine and perfluoroheptanoic acid in the presence of SNs-1(2-6) (Ni, 1 mol\%) in $\mathrm{CH}_{3} \mathrm{CN}$ at the potential of $\mathrm{Ni}^{\mathrm{II}}$ first oxidation peak yields to perfluoroalkylation product. $\mathrm{CO}_{2}$ gas evolution during the electrolysis was observed at room temperature. The isolated yields vary within $27-93 \%$ subject to the nanoparticulate architecture (Table 3 and Fig. 8). Moreover, the low leakage of the $\mathrm{Ni}^{\mathrm{II}}$ complexes from $\mathrm{SNs}-1(2-6)$ enabled the nanoparticles to be recycled and reused 5 times for $\mathrm{C}\left(\mathrm{sp}^{2}\right)-\mathrm{H}$ bond functionalization (Table 3 ). The fluoroalkylated caffeine yield have been decreased by $6-8 \%$ after fifth synthesis with the same nanocatalyst sample.

Table 3 Yield of coupling of caffeine and perfluoroheptanoic acid at $25^{\circ} \mathrm{C}, \mathrm{CH}_{3} \mathrm{CN}$

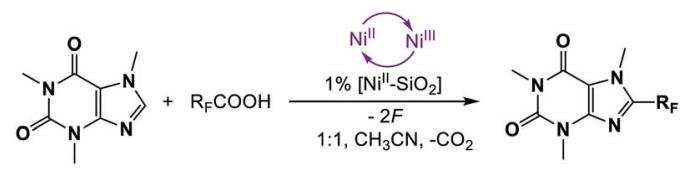

\begin{tabular}{llllll}
\hline & \multicolumn{5}{l}{ Product yields NMR yield (isolated yield), [\%] } \\
\cline { 2 - 6 } & 1st & 2nd & 3rd & 4th & 5th \\
\hline NP type 1 & $70(63)$ & $69(60)$ & $66(56)$ & $64(53)$ & $62(50)$ \\
NP type 2 & $91(75)$ & $91(75)$ & $89(73)$ & $88(73)$ & $87(70)$ \\
NP type 3 & $93(76)$ & $93(76)$ & $92(75)$ & $92(75)$ & $91(73)$ \\
NP type 4 & $45(35)$ & $44(34)$ & $44(32)$ & $42(32)$ & $42(32)$ \\
NP type 5 & $47(38)$ & $46(37)$ & $46(37)$ & $45(34)$ & $45(34)$ \\
NP type 6 & $27(20)$ & $27(20)$ & $27(20)$ & $27(20)$ & $27(20)$
\end{tabular}

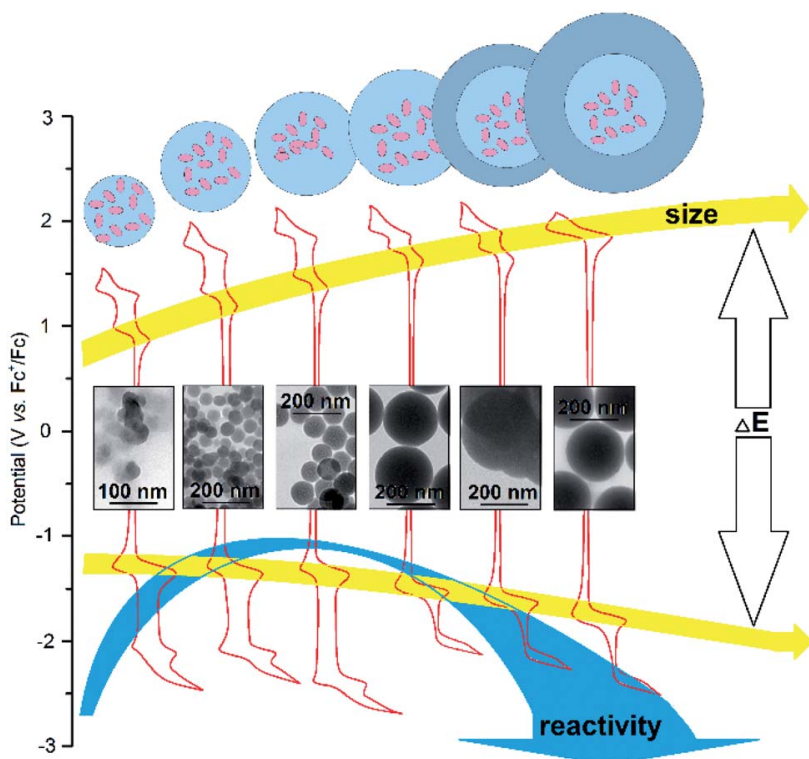

Fig. 8 Nano-architecture of silica nanoparticles doped with $\mathrm{Ni}^{\prime \prime}$ complexes as a tool to tune both electrochemical and catalytic behavior of $\mathrm{Ni}^{\prime \prime}$.

The yield values (Table 3) are greater under the use of SNs$1(2,3)$ than those evaluated for $\operatorname{SNs}-4(5,6)$. This is in good agreement with the difference in their nanoparticulate architecture which, in turn, is the reason for significant decrease of the $\mathrm{Ni}^{\mathrm{II}}$ complexes accessibility to interaction with the substrates. The correlation between the nanoparticulate features of SNs-1(2-6) and their electrochemical and catalytic behavior is illustrated by Fig. 8. The tendency (Table 3 and Fig. 8) highlights the smaller sized SNs-1 $(2,3)$ versus the greater sized SNs-4 $(5,6)$ as more prominent candidates for both facile redox and greater catalytic activities of the nanoparticles. It is also worth noting that both yield and potential values of SNs1(2-6) are affected by the nanoparticulate architecture in the similar way, while the increase of the yield values on going from SNs-1 to SNs-3 disagrees with the tendency.

The disagreement can be explained by the factors beside the size and nano-architecture affecting the catalytic activity of SNs1(2-6) in the acetonitrile solutions.

It is worth assuming the greater aggregation of SNs-1 versus SNs-2(3) as the factor decreasing their catalytic activity, since the greater aggregation of the smaller sized SNs in comparison with the greater sized ones is well documented. ${ }^{52}$

\section{Conclusions}

The present work introduces the well-known Stöber procedure as facile basis for further modification aimed at the embedding of $\mathrm{Ni}^{\mathrm{II}}$ complexes into silica nanoparticles. The easy variation of the synthetic conditions enables to vary the nanoparticulate architecture from "core" to "core-shell" with different silica shell thickness. The analysis of the electrochemical behavior of the nanoparticles with different nano-architecture reveals great impact of the latter on the facility of redox transformations for the $\mathrm{Ni}^{\mathrm{II}}$ complexes within silica nanoparticles. In particular, the 
thickness of silica shell is revealed as the factor controlling the interfacial location of the complexes which, in turn, is the main reason for their redox behavior. Moreover, the results highlight the variation of the nanoparticulate architecture as a powerful tool to modify the catalytic activity of $\mathrm{Ni}^{\mathrm{II}}$ complexes in oxidative $\mathrm{C}-\mathrm{H}$ fluoroalkylation of caffeine. Thus, the revealed regularities provide convenient synthetic tool for controlling the functionality of the nanoparticles by variation of their architecture, which for the best of our knowledge is rather rare documented in literature.

\section{Experimental}

\section{Materials}

Tetraethyl orthosilicate (TEOS, 98\%) and ammonium hydroxide (28-30\%) were purchased from Acros. $\mathrm{C}_{6} \mathrm{~F}_{13} \mathrm{COOH}$ was purchased from $\mathrm{P} \& \mathrm{M}$ Invest and used without further purification. $\mathrm{CH}_{3} \mathrm{CN}$ (CHROMASOLV®) Plus, $\geq 99.9 \%$, by Acros Organics) was used without any preliminary purification. 2.2' bipyridine (99\%, from Acros Organic), and $\mathrm{C}_{6} \mathrm{H}_{6}$ (CHROMASOLV® Plus, $\geq 99.9 \%$, by Sigma Aldrich) were used without any preliminary purification as well.

The ethanol and TEOS were purified by distillation.

$\mathrm{Et}_{4} \mathrm{NBF}_{4}$ was obtained by mixing an aqueous solution of $\mathrm{Et}_{4} \mathrm{NOH}(30-35 \%)$ with $\mathrm{HBF}_{4}$ for to a neutral indicator reaction. $\mathrm{Et}_{4} \mathrm{NBF}_{4}$ precipitated from the reaction mixture as white crystals, which were separated by filtering. The powder salt was further recrystallized from diethyl ether and dried for 2 to 3 days in a vacuum at $55{ }^{\circ} \mathrm{C}$ for dehydration.

Synthesis of $\left[(\mathbf{b p y})_{3} \mathbf{N i}^{\mathbf{I I}}\right]\left(\mathrm{BF}_{4}\right)_{2}$. This complex was prepared by mixing of $\left(\mathrm{H}_{2} \mathrm{O}\right)_{6} \mathrm{Ni}\left(\mathrm{BF}_{4}\right)_{2}(2.00 \mathrm{~g}, 5.9 \mathrm{mmol})$ and 2,2'-bpy $(2.76 \mathrm{~g}$, $17.7 \mathrm{mmol})$ in $\mathrm{CH}_{3} \mathrm{CN}(20 \mathrm{~mL})$. After $3 \mathrm{~h}$ of stirring, $\mathrm{Ni}(\mathrm{II})$ complexes were precipitated from solution by adding diethyl ether, filtered off and air-dried. Yield: $376 \mathrm{~g}$ (91\%) calculated, \%: C 51.41; H 3.45; N 11.99 for $\mathrm{C}_{30} \mathrm{H}_{24} \mathrm{~B}_{2} \mathrm{~F}_{8} \mathrm{~N}_{6} \mathrm{Ni}$. Found, \%: C 51.38; $\mathrm{H} 3.52$; N 12.01 .

Synthesis of NP type 1-3. A solution of TEOS $(1.14 \mathrm{~mL})$ in EtOH $(11.36 \mathrm{~mL})$ was added to $\mathrm{NH}_{4} \mathrm{OH}(28-30 \%)(0.38 \mathrm{~mL})$ in EtOH $(8.05 \mathrm{~mL})-\mathrm{H}_{2} \mathrm{O}(4.05 \mathrm{~mL})$ at the speed $2 \mathrm{~mL}$ per $\mathrm{min}$ (thought syringe pump) under continuous stirring (750 rpm). After 5 minutes of reaction, solution of $\left[\mathrm{Ni}(\mathrm{bpy})_{3}\right]\left(\mathrm{BF}_{4}\right)_{2}$ in $\mathrm{EtOH}$ $(2.5 \mathrm{~mL}, C=4.5 \mathrm{mM})$ was injected into this mixture. After $30 \mathrm{~min}$ (NP type 1), $60 \mathrm{~min}$ (NP type 2), $120 \mathrm{~min}$ (NP type 3) of stirring, Ni(II)-doped silica nanoparticles were precipitated, centrifuging, washing several times by ethanol and water. We used ultrasonication while washing the silica nanoparticles to remove physically absorbed $\mathrm{Ni}$ (II) complex from the particles surfaces. Finally, the NPs were dried.

Synthesis of NP type 4. A solution of TEOS $(1.71 \mathrm{~mL})$ in EtOH $(11.36 \mathrm{~mL})$ was added to $\mathrm{NH}_{4} \mathrm{OH}(28-30 \%)(0.57 \mathrm{~mL})$ in EtOH $(8.05 \mathrm{~mL})-\mathrm{H}_{2} \mathrm{O}(4.05 \mathrm{~mL})$ at the speed $2 \mathrm{~mL}$ per min under continuous stirring (750 rpm). After 5 minutes of reaction, solution of $\left[\mathrm{Ni}(\mathrm{bpy})_{3}\right]\left(\mathrm{BF}_{4}\right)_{2}$ in EtOH $(2.5 \mathrm{~mL}, C=4.5 \mathrm{mM})$ was injected into this mixture. After 6 h of stirring, Ni(II)-doped silica nanoparticles (NP type 4) were precipitated, centrifuging, washing several times by ethanol and water. Finally, the NPs were dried.
Synthesis of NP type 5, 6. A solution of TEOS $(1.14 \mathrm{~mL})$ in EtOH $(11.36 \mathrm{~mL})$ was added to $\mathrm{NH}_{4} \mathrm{OH}(28-30 \%)(0.38 \mathrm{~mL})$ in EtOH $(8.05 \mathrm{~mL})-\mathrm{H}_{2} \mathrm{O}(4.05 \mathrm{~mL})$ at the speed $2 \mathrm{~mL}$ per $\mathrm{min}$ (thought syringe pump) under continuous stirring (750 rpm). After 5 minutes of reaction, solution of $\left[\mathrm{Ni}(\mathrm{bpy})_{3}\right]\left(\mathrm{BF}_{4}\right)_{2}$ in $\mathrm{EtOH}$ $(2.5 \mathrm{~mL}, C=4.5 \mathrm{mM}$ ) was injected into this mixture. After $6 \mathrm{~h}$ of stirring, Ni(II)-doped silica nanoparticles were precipitated, centrifuging, washing several times by ethanol and water. We used ultrasonication while washing the silica nanoparticles to remove physically absorbed $\mathrm{Ni}(\mathrm{II})$ complex from the particles surfaces. Finally, the NPs were dried. A dispersion of NP in EtOH $8.05 \mathrm{~mL}-\mathrm{H}_{2} \mathrm{O} 4.05 \mathrm{~mL}-\mathrm{NH}_{4} \mathrm{OH}$ (28-30\%) $0.19 \mathrm{~mL}$ (or $0.38 \mathrm{~mL}$ for NP type 6) was ultrasonicated 20 minutes. A solution of TEOS $0.57 \mathrm{~mL}$ for NP type 5 (or $1.14 \mathrm{~mL}$ for NP type 6) in EtOH $11.36 \mathrm{~mL}$ was added to dispersion of $\mathrm{NP}$ at the speed $2 \mathrm{~mL}$ per min (thought syringe pump) under continuous stirring (750 rpm). After $6 \mathrm{~h}$ of stirring, Ni(II)-doped silica nanoparticles were precipitated by centrifugation. Silica nanoparticles were washed several times by ethanol and water. Finally, the NPs were dried.

The leaching of $\left[(\mathrm{bpy})_{x} \mathrm{Ni}^{\mathrm{II}}\right]$ complexes from the silica nanoparticles SNs-1-6 was monitored using the following procedure: a dispersion of silica nanoparticles SNs-1-6 in $\mathrm{CH}_{3} \mathrm{CN}(C=0.2 \mathrm{~g}$ $\mathrm{L}^{-1}$ ) was stirred for 1 hour at $750 \mathrm{rpm}$. Afterwards, Ni(II) doped silica nanoparticles SNs-1-6 were precipitated by centrifugation at $12000 \mathrm{rpm}$. The supernatants' absorption spectra after phase separation are shown in Fig. 4.

Synthesis of 8-(perfluorohexyl)caffeine. A solution was prepared for synthesis by mixing $0.0327 \mathrm{~g}\left(0.310^{-5} \mathrm{~mol}\right)$ of Nidoped silica nanoparticles, $0.3 \mathrm{mmol}$ of caffeine, and $0.11 \mathrm{~g}(0.3$ $\mathrm{mmol})$ of $\mathrm{C}_{6} \mathrm{~F}_{13} \mathrm{COOH}$ in $\mathrm{CH}_{3} \mathrm{CN}(50 \mathrm{~mL})$. Electrolysis was performed in an electrochemical cell, separating the anode and cathode compartments at ambient temperature in an argon atmosphere with a working electrode potential of $1.41 \mathrm{~V} v s . \mathrm{Ag} /$ $\mathrm{AgCl}$. The amount of electricity that ended up passing through the electrolyte was $2 \mathrm{~F}$ per mole of $\mathrm{C}_{6} \mathrm{~F}_{13} \mathrm{COOH}$. After completing the electrolysis, the immobilized catalyst was separated by centrifugation and the solution was washed with distilled water $(100 \mathrm{~mL})$ and extracted with benzene (30 mL three times). The organic layer was finally dried with magnesium sulfate and filtered. The residual solution was concentrated under reduced pressure and the products were purified by silica gel column chromatography (ethyl acetate-hexane). Product yields presented in Table 3. $\mathrm{mp}=105-107{ }^{\circ} \mathrm{C} ;{ }^{1} \mathrm{H}$ NMR $(600 \mathrm{MHz}, \mathrm{MeOH}-$ $\left.\mathrm{d}_{4}\right): \delta=4.60(\mathrm{~s}, 3 \mathrm{H}), 3.99(\mathrm{~s}, 3 \mathrm{H}), 3.52(\mathrm{~s}, 3 \mathrm{H}) ;{ }^{13} \mathrm{C} \mathrm{NMR}(100.6$ $\left.\mathrm{MHz}, \mathrm{C}_{6} \mathrm{D}_{6}\right): \delta=156.8,152.9,148.3,111.8,34.4,30.1,28.4 ;{ }^{19} \mathrm{~F}$ NMR (376 MHz, $\left.\mathrm{CDCl}_{3}\right): \delta=-82.4,-109.8,-121.9,-122.6$, -123.8, -127.1; EIMS, $m / z: 512.14[\mathrm{M}]^{+}$. Anal. calc. (\%): C, 32.83; H, 1.77; F, 48.22; N, 10.94; O, 6.25. Found (\%): C, 32.74; H, $1.74 ; \mathrm{N}, 10.93$. The spectroscopic data for 8 -(perfluorohexyl) caffeine matched those previously reported..$^{35}$

\section{Methods}

\section{TEM-EDX experiments}

Experiments were carried out on Hitachi HT7700 transmission electron microscope with energy-dispersive X-ray detector from 
Thermo Scientific. The accelerating voltage was equal $80 \mathrm{kV}$. The accumulation time of one spectrum was $300 \mathrm{~s}$.

UV-Vis spectra were recorded on a Lambda 35 spectrophotometer (PerkinElmer).

$\mathrm{Ni}$ and $\mathrm{Si}$ were identified in the SNs-1-6 colloids using simultaneous inductively coupled plasma atomic emission spectrometry (ICP-AES) model iCAP 6300 DUO by Varian Thermo Scientific Company equipped with a CID detector. This spectrometer enables the simultaneous measurement of peak heights within the 166 to $867 \mathrm{~nm}$ range. The optical resolution is less than $0.007 \mathrm{~nm}$ to $200 \mathrm{~nm}$. As for the working frequency, it is $27.12 \mathrm{MHz}$. Together, the radial and axial view configurations enable optimal peak height measurements with suppressed spectral noises.

\section{Electrosynthesis}

Preparative electrolysises were performed using a B5-49 direct current source in a thermostatically controlled, cylindrical, sectioned $100 \mathrm{~mL}$ electrolyser (a three-electrode cell). Platinum with a surface area of $20 \mathrm{~cm}^{2}$ was used for the cathodes and a platinum rod was used as the anode. The working electrode potential was determined using reference electrode $\mathrm{Ag} / \mathrm{AgCl}$. During electrolysis, the electrolyte was stirred using a magnetic stirrer, the saturated $\mathrm{Et}_{4} \mathrm{NBF}_{4}$ solution in DMF was used as an analyte, and the anode compartment was separated by ceramic membrane. The mass spectra were then recorded in EI mode using ThermoQuest TRACE MS.

\section{NMR measurements}

A NMR measurements were performed in the NMR department (A.E. Arbuzov Institute Organic and Physical Chemistry) of the Federal Collective Spectral Analysis Center for physical and chemical studies on the structure, properties, and composition of matter and materials. NMR experiments were conducted using Bruker spectrometers AVANCE-400 (400.1 $\mathrm{MHz}\left({ }^{1} \mathrm{H}\right)$, 376.5 MHz $\left.\left({ }^{19} \mathrm{~F}\right), 100.6 \mathrm{MHz}\left({ }^{13} \mathrm{C}\right)\right)$ and AVANCE-600 $(600.1 \mathrm{MHz}$ $\left.\left({ }^{1} \mathrm{H}\right), 150.9 \mathrm{MHz}\left({ }^{13} \mathrm{C}\right)\right)$ equipped with a pulsed gradient unit capable of producing magnetic field pulse gradients in the $z$ direction of $53.5 \mathrm{G} \mathrm{cm}^{-1}$. All spectra were acquired in a $5 \mathrm{~mm}$ gradient inverse broad band probe head. As a result, chemical shifts were reported on the $\delta(\mathrm{ppm})$ scale relative to the residual ${ }^{1} \mathrm{H}$ and ${ }^{13} \mathrm{C} \mathrm{C}_{6} \mathrm{D}_{6}$ signal resulting in external $\mathrm{C}_{6} \mathrm{~F}_{6}(-164.9 \mathrm{ppm})$ for ${ }^{19} \mathrm{~F}$ NMR spectra.

\section{Electrochemistry}

Electrochemical measurements were taken on a BASiEpsilonE2P electrochemical analyzer (USA). The program concerned Epsilon-EC-USB-V200 waves. A conventional threeelectrode system was used with glassy carbon for carbon paste electrode (CPE) solutions for powder samples as the working electrode, the $\mathrm{Ag} / \mathrm{AgCl}(0.01 \mathrm{M})$ electrode as the reference electrode, and a Pt wire as the counter electrode. $0.1 \mathrm{M} \mathrm{Et}_{4} \mathrm{NBF}_{4}$ was used as the supporting electrolyte to determine the currentvoltage characteristics.

To study the powder samples, a modified CPE working electrode was used, ${ }^{2,3}$ which was prepared as follows: the carbon particles/phosphonium salt (dodecyl(tri-tert-butyl)phosphonium tetrafluoroborate) composite electrode was prepared using a grinding a mixture of graphite powder and phosphonium salt with a 90/10 (w/w) ratio in mortar giving it a homogeneous mass. ${ }^{56} \mathrm{~A}$ modified electrode was also devised in a similar manner except that a portion (ca. 5\%) of the graphite powder was replaced by the Ni complex (or Ni@SO 2 ) powder under study. As a result, a portion of the resulting paste was packed firmly into the (3 $\mathrm{mm}$ in diameter) a Teflon holder cavity.

\section{Scanning electron microscopy analysis}

In this case, an immobilized catalyst was studied using electron microscopy analysis before and after a perfluoroalkylation reaction. The solutions were applied to the titanium foil surface previously cleared using sonification in acetone. Then, the sample was exsiccated at low heat (no higher than $40{ }^{\circ} \mathrm{C}$ ). The morphology of the sample surfaces was characterized by an SEM plan-view using a high-resolution microscope that Merlin Carl Zeiss combined with ASB (Angle Selective Backscattering) and SE InLens (Secondary Electrons Energy selective Backscattering) detectors, which was also equipped for an energydispersive X-ray spectroscopy (EDX) analysis with an AZTEC XMAX energy-dispersion spectrometer by Oxford Instruments.

\section{Conflicts of interest}

There are no conflicts to declare.

\section{Acknowledgements}

This work was supported by Russian Science Foundation grant no. 19-13-00016. The authors gratefully acknowledge the CSFSAC FRC KSC RAS for the registration of spectra (NMR, IR, etc.).

\section{Notes and references}

1 R. K. Sharma, S. Sharma, S. Dutta, R. Zboril and M. B. Gawande, Green Chem., 2015, 17, 3207-3230.

2 H. Tian, X. Li, L. Zeng and J. Gong, ACS Catal., 2015, 5(8), 4959-4977.

3 J. Wang, L. Liu, X. Dong, L. Alfilfil, C.-E. Hsiung, Z. Liu and Y. Han, Chem. Mater., 2018, 30(18), 6361-6369.

4 T.-Y. Liang, C.-Y. Lin, F.-C. Chou, M. Wang and D.-H. Tsai, J. Phys. Chem. C, 2018, 122(22), 11789-11798.

5 X. Yan, T. Hu, P. Liu, S. Li, B. Zhao, Q. Zhang, W. Jiao, S. Chen, P. Wang, J. Lu, L. Fan, X. Deng and Y.-X. Pan, Appl. Catal., B, 2019, 246, 221-231.

6 S. A. Dergunov, M. D. Kim, S. N. Shmakov and E. Pinkhassik, Acc. Chem. Res., 2019, 52(1), 189-198.

7 T. V. Gryaznova, M. N. Khrizanforov, K. V. Kholin, M. A. Vorotyntsev, K. V. Gor'kov, N. V. Talagaeva, M. V. Dmitrieva, E. V. Zolotukhina and Y. H. Budnikova, Catal. Lett., 2018, 10, 3119-3125.

8 Y. Budnikova, Pet. Chem., 2017, 57(14), 1259-1276. 
9 M. N. Khrizanforov, S. V. Fedorenko, A. R. Mustafina, K. V. Kholin, I. R. Nizameev, S. O. Strekalova, V. V. Grinenko, T. V. Gryaznova, R. R. Zairov, R. Mazzaro, V. Morandi, A. Vomiero and Y. H. Budnikova, Dalton Trans., 2018, 47, 9608-9616.

10 S. Fedorenko, M. Jilkin, N. Nastapova, V. Yanilkin, O. Bochkova, V. Buriliov, I. Nizameev, G. Nasretdinova, M. Kadirov, A. Mustafina and Y. Budnikova, Colloids Surf., A, 2015, 486(5), 185-191.

11 S. V. Fedorenko, M. E. Jilkin, T. V. Gryaznova, E. O. Iurko, O. D. Bochkova, A. R. Mukhametshina, I. R. Nizameev, K. V. Kholin, R. Mazzaro, V. Morandi, A. Vomiero, A. R. Mustafina and Y. H. Budnikova, Colloid Interface Sci. Commun., 2017, 21, 1-5.

12 U. Kreibig and M. Vollmer, Optical Properties of Metal Clusters, Springer-Verlag, Heidelberg, Germany, 1995, vol. 25.

13 N. Toshima and T. Yonezawa, New J. Chem., 1998, 22, 11791201.

14 A. R. Tao, S. Habas and P. Yang, Small, 2008, 4, 310-325.

15 L. M. Liz-Marzán, Langmuir, 2006, 22, 32-41.

16 C. Burda, X. Chen, R. Narayanan and M. A. El-Sayed, Chem. Rev., 2005, 105, 1025.

17 M. A. Mahmoud, C. E. Tabor, Y. Ding, Z. L. Wang and M. A. El-Sayed, J. Am. Chem. Soc., 2008, 130, 4590.

18 H. Lee H, S. E. Habas, S. Kweskin, D. Butcher, G. A. Somorjai and P. Yang, Angew. Chem., Int. Ed., 2006, 118, 7988-7992.

19 H. Lee H, S. E. Habas, S. Kweskin, D. Butcher, G. A. Somorjai and P. Yang, Angew. Chem., Int. Ed., 2006, 45, 7824.

20 K. M. Bratlie, H. Lee, K. Komvopoulos, P. Yang and G. A. Somorjai, Nano Lett., 2007, 7, 3097.

21 S. Z. Tasker, E. A. Standley and T. F. Jamison, Nature, 2014, 509, 299-309.

22 N. M. Camasso and M. S. Sanford, Science, 2015, 347(6227), 1218-1220.

23 Z. Ruan, S. Lackner and L. Ackermann, Angew. Chem., Int. Ed., 2016, 55(9), 3153-3157.

24 Z. Ruan, D. Ghorai, G. Zanoni and L. Ackermann, Chem. Commun., 2017, 53(65), 9113-9116.

25 Z. Ruan, S. Lackner and L. Ackermann, ACS Catal., 2016, 6(7), 4690-4693.

26 Y. Fang, T. Rogge, L. Ackermann, S. Y. Wang and S. J. Ji, Nat. Commun., 2018, 9(1), 2240.

27 W. Song, S. Lackner and L. Ackermann, Angew. Chem., Int. Ed., 2014, 53(9), 2477-2480.

28 Yu. B. Dudkina, D. Y. Mikhaylov, T. V. Gryaznova, O. G. Sinyashin, D. A. Vicic and Yu. H. Budnikova, Eur. J. Org. Chem., 2012, 11, 2114-2117.

29 Y. B. Dudkina, M. N. Khrizanforov, T. V. Gryaznova and Y. H. Budnikova, J. Organomet. Chem., 2014, 751, 301-305.

30 D. Y. Mikhaylov, Y. H. Budnikova, T. V. Gryaznova, Y. Dudkina, M. N. Khrizanphorov, O. Kataeva and D. A. Vicic, Dalton Trans., 2012, 4(1), 165-172.

31 Y. B. Dudkina, R. R. Fayzullin, K. A. Lyssenko, A. T. Gubaidullin, K. V. Kholin, A. I. Levitskaya, M. Yu. Balakina and Y. H. Budnikova, Organometallics, 2019, 38(6), 1254-1263.
$32 \mathrm{Yu}$. H. Budnikova, Yu. M. Kargin, J. Perichon and J.-Y. Nedelec, J. Organomet. Chem., 1999, 575, 63-66.

$33 \mathrm{Yu}$. H. Budnikova, J. Perichon, D. G. Yakhvarov, Yu. M. Kargin and O. G. Sinyashin, J. Organomet. Chem., 2001, 630, 185-192.

34 A. Klein, Y. H. Budnikova and O. G. Sinyashin, J. Organomet. Chem., 2007, 692, 3156-3166.

35 M. N. Khrizanforov, S. V. Fedorenko, S. O. Strekalova, K. V. Kholin, A. R. Mustafina, M. Y. Zhilkin, V. V. Khrizanforova, Y. N. Osin, V. V. Salnikov, T. V. Gryaznova and Y. H. Budnikova, Dalton Trans., 2016, 45(30), 11976-11982.

36 P. Ryabchuk, G. Agostini, M.-M. Pohl, H. Lund, A. Agapova, H. Junge, K. Junge and M. Beller, Sci. Adv., 2018, 4, eaat0761.

37 M. Yadav and R. K. Sharma, Curr. Opin. Green Sustain. Chem., 2019, 15, 47-59.

38 Y. B. Dudkina, T. V. Gryaznova, Y. N. Osin, V. V. Salnikov, N. A. Davydov, S. V. Fedorenko, A. R. Mustafina, D. A. Vicic, O. G. Sinyashin and Y. H. Budnikova, Dalton Trans., 2015, 44, 8833-8838.

39 W. Stöber, A. Fink and E. Bohn, J. Colloid Interface Sci., 1968, 26, 62-69.

40 K. Nozawa, H. Gailhanou, L. Raison, P. Panizza, H. Ushiki, E. Sellier, J. P. Delville and M. H. Delville, Langmuir, 2005, 21(4), 1516-1523.

41 D. L. Green, J. S. Lin, Y.-F. Lam, M. Z.-C. Hu, D. W. Schaefer and M. T. Harris, J. Colloid Interface Sci., 2003, 266(2), 346358.

42 A. R. Mustafina, S. V. Fedorenko, O. D. Konovalova, A. Yu. Menshikova, N. N. Shevchenko, S. E. Soloveva, A. I. Konovalov and I. S. Antipin, Langmuir, 2009, 25(5), 3146-3151.

43 A. R. Mukhametshina, A. R. Mustafina, N. A. Davydov, S. V. Fedorenko, I. R. Nizameev, M. K. Kadirov, V. V. Gorbatchuk and A. I. Konovalov, Langmuir, 2015, 31(1), 611-619.

44 D. Zhang, Z. Wu, J. Xu, J. Liang, J. Li and W. Yang, Langmuir, 2010, 26(9), 6657-6662.

45 S. Fedorenko, A. Stepanov, R. Zairov, O. Kaman, R. Amirov, I. Nizameev, K. Kholin, I. Ismaev, A. Voloshina, A. Sapunova, M. Kadirov and A. Mustafina, Colloids Surf., A, 2018, 559, 60-67.

46 J. Ho, M. L. Coote, C. J. Cramer and D. G. Truhlar, Theoretical Calculation of Reduction Potentials, in Organic Electrochemistry, ed. O. Hammerich and B. Speiser, CRC Press, Boca Raton, FL, 5th edn, 2016, pp. 229-259.

47 A. Dey, F. E. Jenney Jr, M. W. W. Adams, E. Babini, Y. Takahashi, K. Fukuyama, K. O. Hodgson, B. Hedman and E. I. Solomon, Science, 2007, 318, 1464-1468.

48 M. L. Pegis, J. A. S. Roberts, D. J. Wasylenko, E. A. Mader, A. M. Appel and J. M. Mayer, Inorg. Chem., 2015, 54, 11883-11888.

49 D. Ajloo, B. Yoonesi and A. Soleymanpour, Int. J. Electrochem. Sci., 2010, 5, 459-477.

50 G. Gritzner, J. Electroanal. Chem., 1983, 144, 259-277.

51 S. V. Fedorenko, S. L. Grechkina, A. R. Mustafina, K. V. Kholin, A. S. Stepanov, I. R. Nizameev, I. E. Ismaev, 
M. K. Kadirov, R. R. Zairov, A. N. Fattakhova, R. R. Amirov and S. E. Soloveva, Colloids Surf., B, 2017, 149, 243-249.

52 S. V. Fedorenko, A. R. Mustafina, A. R. Mukhametshina, M. E. Jilkin, T. A. Mukhametzyanov, A. O. Solovieva, T. N. Pozmogova, L. V. Shestopalova, M. A. Shestopalov, K. V. Kholin, Y. N. Osin and O. G. Sinyashin, Mater. Sci. Eng., C, 2017, 76, 551-558.

53 W. Ramsay and R. Foster, Nature, 1949, 163, 178-179.

54 Y. B. Dudkina, K. V. Kholin, T. V. Gryaznova, D. R. Islamov, O. N. Kataeva, I. Kh. Rizvanov, A. I. Levitskaya,
O. D. Fominykh, M. Yu. Balakina, O. G. Sinyashin and Y. H. Budnikova, Dalton Trans., 2017, 46, 165-177.

55 A. A. Kalinin, S. M. Sharipova, T. I. Burganov, Y. B. Dudkina, A. R. Khamatgalimov, S. A. Katsyuba, Y. H. Budnikova and M. Yu. Balakina, Dyes Pigm., 2017, 146, 82-91.

56 M. N. Khrizanforov, D. M. Arkhipova, R. P. Shekurov, T. P. Gerasimova, V. V. Ermolaev, D. R. Islamov, V. A. Miluykov, O. N. Kataeva, V. V. Khrizanforova, O. G. Sinyashin and Y. H. Budnikova, J. Solid State Electrochem., 2015, 19, 2883-2890. 